\title{
STUDI TENTANG BERBAGAI TIPE BAHAN BAKAR TERHADAP PRESTASI MESIN MOBIL TOYOTA XXX
}

\author{
Audri D Cappenberg \\ Jurusan Teknik Mesin, Fakultas Teknik, Universitas 17 Agustus 1945 \\ Alamat Email : audri.cappenberg@uta45jakarta.ac.id
}

\begin{abstract}
ABSTRAK
Perkembangan industri otomotif semakin meningkat dari tahun ke tahun, dan diikuti dengan penggunaan kendaraan baik roda dua maupun roda empat yang semakin meningkat bersamaan dengan itugas buang kendaraan semakin tinggi dan berdampak pada tingkat pencemaran lingkungan yang meningkat drastis sejak tahun 2011. Gas buang kendaraan dapat merusak lingkungan karena tingkat emisiyang tinggi yang diakibatkan karena pembakaran yang tidak sempurna yang terjadi pada motor. Ketidaksempurnaan pembakaraan pada motor dapat diakibatkan oleh beberapa hal diantaranya sistem pembakaran yang kurang baik dan penggunaan bahan bakar yang kurang berkualitas. Dari hasil penelitian yang dilakukan terhadap bahan bakar premium, pertamax dan pertamax plus, maka didapatkan bahwa untuk bahan bakar jenis pertamax plus memiliki daya mesin, efisiensi mekanis dan efisiensi termal lebih besar dari kedua jenis bahan bakar lainnya, dan penggunaan bahan bakar lebih hemat, serta tingkat emisi yang rendah.
\end{abstract}

Kata kunci ; pertamax plus, prestasi mesin dan emisi gas buang.

\section{PENDAHULUAN}

\section{I.1. Latar Belakang}

Pertumbuhanproduksi industri otomotif di Indonesia semakin meningkat dan diikuti dengan dimulainya produksi Low Cost Green Car(LCGC) secara prototype oleh produsen kendaraan roda empat ( Daihatshu dan Toyota ). Memproduksi kendaraan murah dan ramah lingkungan sudah menjadi kebutuhan yang mendesak, mengingat tingkat pencemaran lingkungan semakin tinggi. Namun sampai dengan saat ini hal tersebut belum terpenuhi, khusus untuk kendaraan roda dua dan roda empat, sehingga pencemaran udara akibat gas buang kendaraan bermotor semakin meningkat, khususnya di daerah Jakarta dan sekitarnya.

Tingkat pencemaran udara di Jakarta meningkat drastis, mulai dari tahun 2011, yang diakibatkan karena uji emisi yang tidak tertib dan meningkatnya populasi kendaraan bermotor .

Berbagai regulasi pemerintah tentang pencemaran udara telah ditetapkan, tapi belum banyak memberikan solusi.Disamping ketersediaan bahan bakar berkualitas di pasaran masih cukup mahal.Sehingga pengguna kendaraan bermotor roda dua maupun roda empat cenderung menggunakan bahan bakar yang murah dengan kualitas yang rendah.

Para pemilik dan pengguna kendaraan bermotor mungkin belum memahami efek penggunaan bahan bakar, baik untuk kendaraannya sendiri, maupun terhadap lingkungan, juga kesehatannya.
Sampai dengan saat ini penggunaan premium masih lebih dominan dibanding penggunaan pertamax dan pertamax plus.

Penggunaan alat pengendali emisi gas buang seperti catalyticconverter dapat mengurangi lebih dari $90 \%$ emisi gas buang yang dihasilkan namun harus memanfaatkan bahan bakar tanpa timbal.Juga terdapat beberapa kendala teknis dalam penggunaan alat pengendali ini seperti terbatasnya keefektifan hanya pada rentang Air Fuel Ratio (AFR) di sekitar stokiometrik.

\subsection{Tujuan}

Penelitian ini bertujuan untuk mengetahui kinerja mesin yang menggunakan premium, pertamax dan pertamax Plus, serta perbandingan kadarCO, $\mathrm{HC}, \mathrm{CO} 2$ dan $\mathrm{O} 2$ dan menentukan bahan bakar yang tepat digunakan sesuai standar emisi yang ditetapkan.

\section{TEORI DASAR}

\subsection{Sistem Bahan Bakar Pada Mesin}

Sistem bahan bakar suatu mesin terdiri dari sistem suplai bahan bakar dan sistem penakar bahan bakar. Sistem suplai bahan bakar berfungsi mengalirkan bahan bakar dari tangki bahan bakar ke sistem penakar bahan bakar. Sistem penakar bahan bakar pada mesin berfungsi sebagai berikut :

1. Penakar jumlah udara dan bahan bakar agar diperoleh campuran udara bahan bakar yang dapat dibakar dengan cepat dan sempurna didalam silinder. 
2. Atomisasi dan penyebar bahan bakar didalam aliran udara atau dikenal dengan Air Fuel Ratio (AFR).

Nilai perbandingan teoritis untuk proses pembakaran sempurna ( AFR stoikiometri) untuk mesin bensin sekitar 14,7. Sistem bahan bakar harus mampu menghasilkan perbandingan udara bahan bakar yang dibutuhkan disilinder yang sesuai dengan kondisi operasi mesin.Pengguaan EFI (Electronic Fuel Injection), adalah salah satu upaya untuk menjamin perbandingan bahan bakar dan udara (Air Fuel Ratio) yang masuk ke mesin, serta peningkatan prestasi msin dan mengurangi emisi gas buang.

\subsection{Sistem Injeksi Bahan Bakar (EFI)}

Sistem injeksi bahan bakar EFI (Electronic Fuel Injection) dikontrol oleh Electronic ControlModule (ECM) atau disebut juga Electronic Control Unit (ECU), yaitu berupa chips yang terdiri dari microprosessor dan memory yang dipasang on board pada mobil. ECU ini menerima input berupa sinyal-sinyal elektronik dari semua sensor dan memprosesnya untuk menentukan jumlah bahan bakar yang diperlukan dan mengatur bukaan katup pada injector.

Penggunaan sistem enjeksi bahan bakar, EFI mempunyai keuntungan sebagai berikut:

1. Memungkinkan pembentukan campuran yang homogen pada setiap silinder

2. Perbandingan bahan bakar dan udara dapat diperoleh pada semua tingkat rpm mesin

3. Respon yang baik sesuai dengan perubahan throttle

4. Koreksi campuran bahan bakar udara

5. Efisiensi pemasukan campuran bahan bakar dan udara lebih banyak

\subsection{Sistem Bahan Bakar Bensin}

Sistem bahan bakar berfungsi untuk menyalurkan sejumlah bahan bakar bensin ke aliran udara di intake port melalui injector yang dikontrol secara elektronik sesuai dengan beban dan putaran mesin.Sistem bahan bakar terdiri dari peralatan mekanis dan elektronik yang menyalurkan sejumlah bahan bakar bensin dari fuel tank hingga injektor.

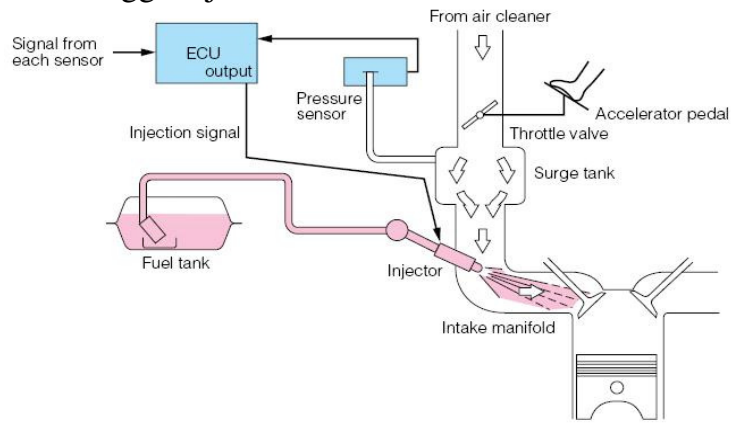

Gambar 1. Konstruksi Sistem Bahan Bakar.
Salah satu cara untuk menaikkan efisiensi motor adalah dengan menaikkan perbandingan kompresinya serta mengurangi terjadinya detonasi (knocking). Bensin dengan angka oktan yang tinggi akan mampu mengatasi detonasi

Makin besar angka oktan, makin besar pula kemampuan bertahan bensin terhadap detonasi (knocking), jadi makin tinggi angka oktannya makin kecil kemungkinan terjadinya detonasi (knocking). Dengan berkurangnya intensitas untuk berdetonasi ini, maka campuran udara dan bahan bakar yang dikompresikan menjadi lebih banyak, sehingga tenaga motor akan lebih besar dan pemakaian bahan bakar menjadi lebih hemat. Angka oktan tergantung pada struktur senyawa hidrokarbon yang terdapat pada bensin. Anti detonasi dari bahan bakar (bensin) diukur dengan mesin CFR (Cooperative Fuel Research Engine) dimana harga perbandingan kompresi mesin ini dapat diubah-ubah sesuai dengan kebutuhan. Penyelidikan angka oktan suatu bahan bakar dilakukan dengan cara membandingkan sifat anti detonasibahan bakar tersebut dengan bahan bakar standar. Dari hasil perbandingan ini akan diketahui berapa nilai angka oktan dari bahan bakar yang diteliti.

Besarnya angka oktan bahan bakar ini tergantung pula pada presentase iso oktan dan normal heptan yang terkandung didalamnya. Jika di dalam suatu bahan bakar terkandung $80 \%$ iso oktan dan $20 \%$ normal heptan maka dapat dikatakan bahwa angka oktan bahan bakar tersebut adalah 80 . Iso oktan mempunyai sifat anti knocking dan nilai tingkat oktannya adalah 100 sedangkan oktan heptan cenderung terhadap knocking dan tingkat oktannya adalah nol. Penambahan iso oktan di dalam bensin akan menambah dan menghemat pemakaian bahan bakar. Karena dengan bertambahnya iso oktan bertambah pula angka oktan.Angka oktan ini dapat pula diperbesar dengan menambahkan anti knock agent yang berupa Tetra Ethyl Lead. Untuk motor bensin dengan perbandingan kompresi yang tinggi diperlukan bahan bakar dengan angka oktan yang tinggi pula. Jadi bensin dengan angka oktan tinggi tidak menguntungkan jika dipakai pada motor bensin yang berkompresi rendah. Biasanya angka oktan rekomendasi pabrik dicantumkan dalam buku manual maupun di dekat tutup tangki bensin mobil. Ada dua cara yang digunakan untuk mengukur nilai oktan :research method dan motor method. Yang paling umum digunakan adalah research method, dan spesifikasi nilai oktannya dengan metoda ini ditetapkan dengan istilah "RON" (Research Octane Number).

Nilai mutu jenis bensin dihitung berdasarkan nilai RON (Research Otcane Number), dan dibedakan menjadi 3 jenis yaitu: 
$\square \square$ Premium (RON 88) :Premium adalah bahan bakar minyak jenis distilat berwarna kekuningan yang jernih. Warna kuning tersebut akibat adanya zat pewarna tambahan (dye). Penggunaan premium pada umumnya adalah untuk bahan bakar kendaraan bermotor bermesin bensin, seperti : mobil, sepeda motor, motor tempel dan lain-lain. Bahan bakar ini sering juga disebut motor gasoline atau petrol.

$\square \square$ Pertamax (RON 92) :ditujukan untuk kendaraan yang mempersyaratkan penggunaan bahan bakar beroktan tinggi dan tanpa timbal (unleaded). Pertamax juga direkomendasikan untuk kendaraan yang diproduksi diatas tahun 1990 terutama yang telah menggunakan teknologi setara dengan electronic fuel injection dan catalytic converters.

$\square \square$ Pertamax Plus (RON 95) :Jenis BBM ini telah memenuhi standar performance International World Wide Fuel Charter (WWFC). Ditujukan untuk kendaraan yang berteknologi mutakhir yang mempersyaratkan penggunaan bahan bakar beroktan tinggi dan ramah lingkungan. Pertamax Plus sangat direkomendasikan untuk kendaraan yang memiliki kompresi ratio > 10,5 dan juga yang menggunakan teknologi Electronic FuelInjection (EFI), Variable Valve Timing Intelligent (VVTI), (VTI), Turbochargers dan catalytic converters

\subsection{Komposisi dan Prilaku Gas Buang Kendaraan Bermotor}

Pada keadaan ideal, mesin kendaraan bermotor dengan komposisi campuran bahan bakar pada kondisi stoikoimetrik $(\mathrm{AFR}=14,7)$ dan pembakaran yang terjadi adalah pembakaran sempurna akan menghasilkan emisi gas buang yang mengandung karbondioksida (CO2), uap air (H2O) dan nitrogen (N2). Dalam kondisi aktual, mesin kendaraan bermotor didesain untuk komposisi campur bahan bakar miskin/kurus (lean mixture), misalnya pada kondisi AFR 12,5 untuk menghidupkan mesin kendaraan bermotor pada saat dingin dan menghasilkan daya maksimal selama kendaraan berakselerasi. Proses pembakaran pada kendaraan bermotor hampir tidak pernah berlangsung dengan sempurna, sehingga emisi gas buang yang dihasilkan juga mengandung karbon monoksida (CO), sisa bahan bakar yang tidak ikut terbakar (hidrokarbon), hidrogen dan beberapa senyawa oksigen (oksida) seperti NOxdengan konsentrasi yang berbeda-beda, tergantung dari kondisi campuran bahan bakar.

Bahan pencemar yang terutama terdapat di dalam gas buang kendaraan bermotor adalah karbon monoksida (CO), berbagai senyawa hidrokarbon, berbagai senyawa nitrogen (NOx) dan sulfur (SOx), dan partikulat debu termasuk timbal (PB).Bahan bakar tertentu hidrokarbon dan timbal organik, di lepaskan ke udara karena adanya penguapan dari sistem bahan bakar. Setelah berada di udara, beberapa senyawa yang terkandung dalam gas buang kendaraan bermotor dapat berubah karena terjadinya reaksi, misalnya dengan sinar matahari dan uap air, atau juga antara senyawasenyawa tersebut satu sama lain.

Proses reaksi tersebut ada yang berlangsung cepat dan terjadi saat itu juga di lingkungan jalan raya, dan adapula yang berlangsung dengan lambat.

Reaksi kimia di atmosfer kadangkala berlangsung dalam suatu rangtai reaksi yang panjang dan rumit, dan menghasilkan produk akhir yang dapat lebih aktif atau lebih lemah dibandingkan senyawa aslinya. Sebagai contoh, adanya reaksi di udara yang mengubah nitrogen monoksida (NO) yang terkandung di dalam gas buang kendaraan bermotor menjadi nitrogen dioksida (NO2) yang lebih reaktif, dan reaksi kimia antara berbagai oksida nitrogen dengan senyawa hidrokarbon yang menghasilkan ozon dan oksida lain, yang dapat menyebabkan asap awan fotokimia (photochemical smog). Pembentukan smog ini kadang tidak terjadi di tempat asal sumber (kota), tetapi dapat terbentuk di pinggiran kota. Jarak pembentukan smog ini tergantung pada kondisi reaksi dan kecepatan angin.Untuk bahan pencemar yang sifatnya lebih stabil seperti timbal $(\mathrm{Pb})$, beberapa hidrokarbon-halogen dan hidrokarbon poliaromatik, dapat jatuh ke tanah bersama air hujan atau mengendap bersama debu, dan mengkontaminasi tanah dan air.Emisi gas buang kendaraan bermotor juga cenderung membuat kondisi tanah dan air menjadi asam.

\subsection{Emisi Gas Buang Motor Bensin}

Emisi adalah suatu zat, energi dan komponen lain yang dihasilkan oleh suatu kegiatan yang dibuang ke udara ambien. Udara ambien adalah udara bebas dipermukaan bumi yang merupakan bagian dari biosfir yang berada dalam wilayah yurisdiksi Republik Indonesia yang dibutuhkan serta mempengaruhi kehidupan manusia, mahluk hidup dan benda lain disekitarnya. Maka yang dimaksud emisi gas buang itu adalah gas atau asap yang dikeluarkan dari pipa gas buang kendaraan bermotor. Beberapa aktivitas kendaraan bermotor akan menimbulkan beberapa jenis pencemar udara.

\subsection{Strategi menurunkan emisi gas buang}

Gas buang yang dikeluarkan kendaraan bermotor, sebagian beracun dan sebagian berupa gas rumah kaca, yang kemudian mengakibatkan pemanasan global., untuk itu perlu diatasi dengan strategi berikut, diantaranya : 
1. Menetapkan standar euro dan meningkatkan teknologi

2.. Peningkatan kualitas bahan bakar

$\square \square$ Optimasi kualitas bahan bakar

$\square \square$ Pengembangan bahan bakar nabati

$\square \square$ Pengembangan bahan bakar alternative

\section{PENGAMBILAN DATA}

\subsection{Persiapan Penelitian}

1. menyiapkan alat dan bahan uji

2. memeriksa sistem bahan bakar dari kendaraan yang akan diuji

3. melakukan percobaan

\subsection{Alat yang digunakan}

Alat uji yang digunakan untuk uji emisi adalah alat Qrotech tipe QRO - 401 buatan Korea.

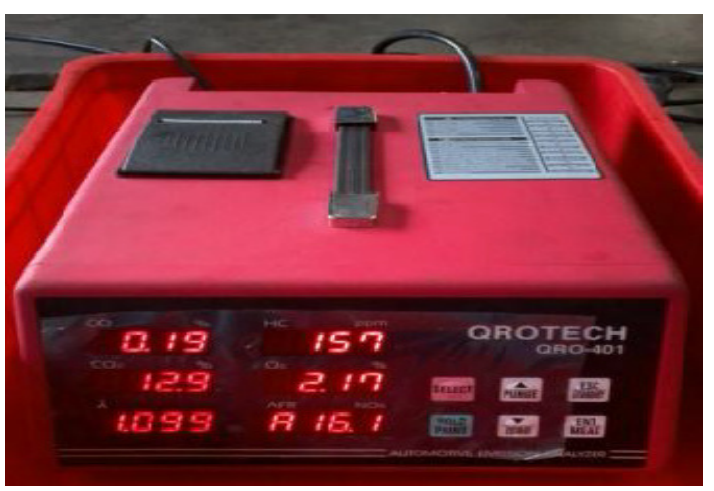

Gambar 3.1. Alat uji Emisi

\subsection{Prosedur Pengambilan Data} berikut :

Cara kerja alat uji emisi tersebut sebagai

1. Menghidupkan mesin

Tekan tombol on pada mesin uji emisi, kemudian tunggu sekitar 2 menit sampai monitor indikasi memprogram, kemudian dilakukan pengambilan data.

2. Masukkan test probe sekurang - kurangnya $40 \mathrm{~cm}$ ke dalam pipa gas buang pada mobil.

a. Bila probe tidak dapat masuk jauh, gerakan maju dan mundur untuk memastikan bahwa nilai yang ditunjukkan tidak berubah.

b. Selama pengukuran, putaran mesin jangan dinaikkan.

3. Tekan tombol zero untuk melihat program test emisi, lalu tunggu selama 30 detik.

4. Tekan enter untuk memulai pengukuran test emisi sampai 30 detik, lalu lakukan penyetelan jika diperlukan.

5. Tekan tombol print untuk melihat hasil dari pengujian emisi tersebut.

\subsection{Prosedur Pengujian Emisi}

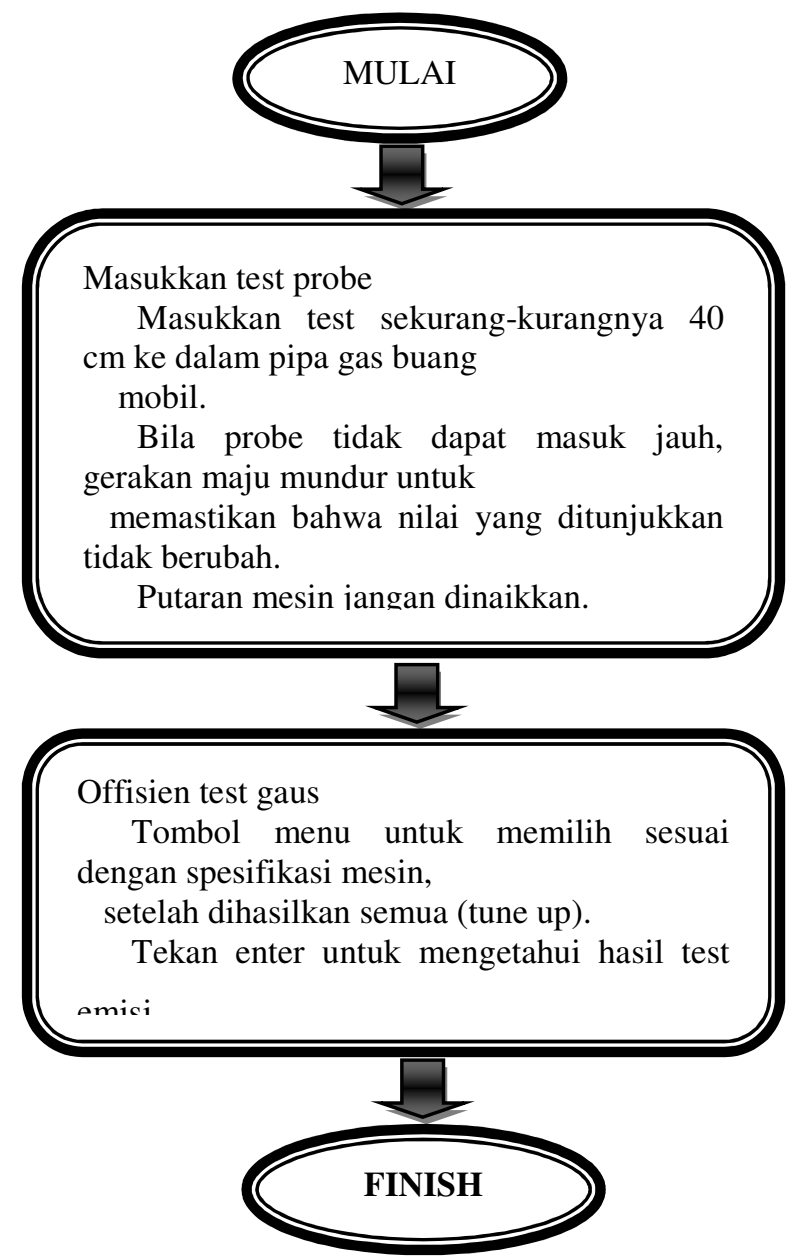

Gambar 3.2. Prosedur Pengujian Emisi

\section{PERHITUNGAN DAN PEMBAHASAN}

\subsection{Data hasil penelitian.}

Tabel 4.1. Data hasil penelitian Kadar Emisi pada Kendaraan

\begin{tabular}{|c|l|l|l|l|}
\hline No & $\begin{array}{l}\text { Unsur - unsur } \\
\text { yang diukur }\end{array}$ & Satuan & Karburator & Injeksi \\
\hline 1. & $\begin{array}{l}\text { Co (Carbon } \\
\text { Monoksida) }\end{array}$ & $\%$ & Max 4 & $\begin{array}{l}\text { Max } \\
3.5\end{array}$ \\
\hline 2. & $\begin{array}{l}\text { HC } \\
\text { (Hydrocarbon) }\end{array}$ & Rpm & Max 400 & $\begin{array}{l}\text { Max } \\
300\end{array}$ \\
\hline 3. & $\begin{array}{l}\text { CO2 (Carbon } \\
\text { Dioksida) }\end{array}$ & $\%$ & $12-16$ & $\begin{array}{l}12- \\
16\end{array}$ \\
\hline 4. & O2 (Oksigen) & $\%$ & Max 2 & Max 2 \\
\hline
\end{tabular}

\subsection{Uji Emisi Gas Buang Pada Kendaraan}

Hasil Uji Emisi pada mobil Toyota XXX kapasitas 1300 adalah sebagai berikut :

1. Premium

$\square \square \mathrm{CO}: 0.03 \%$; batas maksimum $3.5 \%$ 
HC : 21 ppm; batas mmaksimum 300 ppm

CO2 : $14.1 \%$; batas maksimum $16 \%$

$\mathrm{O} 2$ : $0.08 \%$; batas maksimum $2 \%$

Secara keseluruhan dari hasil uji emisi untuk semua komponen dapat dikategorikan normal

2. Menggunakan Bahan Bakar Pertamax

$\square \square \mathrm{CO}: 0.02 \%$; batas maksimum $3.5 \%$

$\square \mathrm{HC}: 19 \mathrm{ppm}$; batas mmaksimum $300 \mathrm{ppm}$

CO2 : $14.1 \%$; batas maksimum $16 \%$

$\square \square \mathrm{O} 2: 0.05 \%$; batas maksimum $2 \%$

Secara keseluruhan dari hasil uji emisi untuk semua komponen dapat dikategorikan normal

3. Menggunakan Bahan Bakar Pertamax Plus

$\square \square \mathrm{CO}: 0.02 \%$; batas maksimum $3.5 \%$

$\square \square \mathrm{HC}: 0 \mathrm{ppm}$; batas maksimum $300 \mathrm{ppm}$

$\square \square \mathrm{CO} 2$ : $14.1 \%$; batas maksimum $16 \%$

$\square \square \mathrm{O} 2: 0.05 \%$; batas maksimum $2 \%$

Secara keseluruhan dari hasil uji emisi untuk semua komponen dapat dikategorikan normal

\subsection{Hasil Penelitian Kadar Emisi Gas Buang}

Ada 5 unsur dalam gas buang kendaraan yang akan diukur yaitu senyawa $\mathrm{HC}, \mathrm{CO}, \mathrm{CO}, \mathrm{O} 2$ dan senyawa NOx. Untuk itu pada penelitian ini akan dicari kadar emisi $\mathrm{CO}, \mathrm{HC}, \mathrm{CO} 2$ dan $\mathrm{O} 2$ dari jenis bahan bakar premium, pertamax, dan pertamax plus di sesuaikan dengan standar emisi yang ada.

Tabel4.2 Standar hasil uji emisi

\begin{tabular}{|l|l|r|r|c|}
\hline \multirow{2}{*}{$\begin{array}{l}\text { JENIS } \\
\text { BAHAN } \\
\text { BAKAR }\end{array}$} & \multicolumn{4}{|l|}{ EMISI } \\
\cline { 2 - 5 } & \multicolumn{1}{|l|}{ CO } & \multicolumn{1}{l|}{ HC } & CO 2 & O 2 \\
\hline Premium & 0.03 & 21 & 14.1 & 0.08 \\
\hline Pertamax & 0.02 & 19 & 14.1 & 0.05 \\
\hline Pertamax Plus & 0.02 & 0 & 14.1 & 0.05 \\
\hline
\end{tabular}

Tabel 4.3Data hasil Penelitian

\begin{tabular}{|l|c|c|c|}
\hline $\begin{array}{l}\text { Data } \\
\text { penelitian }\end{array}$ & Premium & Pertamax & $\begin{array}{l}\text { Pertamax } \\
\text { Plus }\end{array}$ \\
\hline $\begin{array}{l}\text { Tekanan } \\
\text { indikator, } \\
\mathrm{kg} / \mathrm{cm}^{2}\end{array}$ & 6,2 & 6,7 & 7,22 \\
\hline $\begin{array}{l}\text { Tekanan } \\
\text { efektif, } \\
\mathrm{kg} / \mathrm{cm}^{2}\end{array}$ & 8,1 & 8,17 & 8,47 \\
\hline
\end{tabular}

\subsection{Menghitung perbandingan udara dan bensin :}

Udara kering mengandung :

Oksigen (O) $21 \%$

Nitrogen (N) 78,03\%

Argon (Ar) 0,94\%
C Dioxside $0,03 \%$

Berat atom : $\quad \mathrm{C}=12$

$\mathrm{H}=1$

$\mathrm{O}=16$

Berat molekul udara $\mathrm{M}$ udara $=29$

Pada pembakaran $\mathrm{C} 8 \mathrm{H} 18$ didapat :

$\mathrm{C} 8 \mathrm{H} 18+\mathrm{O} 2+\mathrm{N} 2 \rightarrow \mathrm{CO} 2+\mathrm{H} 2 \mathrm{O}+\mathrm{N} 2$

$\mathrm{C} 8 \mathrm{H} 18+12,5 \mathrm{O} 2+47 \mathrm{~N} 2 \rightarrow 8 \mathrm{CO} 2+9 \mathrm{H} 2 \mathrm{O}+47$

$\mathrm{N} 2$

$8 \mathrm{C} 8 \mathrm{H} 18+25 \mathrm{O} 2+94 \mathrm{~N} 2 \rightarrow 16 \mathrm{CO} 2+18 \mathrm{H} 2 \mathrm{O}+94 \mathrm{~N} 2$

Berat udara $=$ Berat molekul O2 + Berat molekul $\mathrm{N} 2 \times$ Berat molekul udara

$$
=(25+94) \times 28,967
$$

Berat bahan bakar $=$ Berat molekul $\mathrm{C} 8 \times$ Berat atom $\mathrm{C}+$ Berat molekul $\mathrm{H} 18 \times$ Berat atom $\mathrm{H}$ $=(16 \times 18)+(36 \times 1.008)$

Air Fuel Ratio (A/F)

$$
=\frac{(25+94) \times 28.967}{(16 \times 18)+(36 \times 1.008)}=15.1
$$

\subsection{Perhitungan kinerja mesin Toyota XXX yang menggunakan premium}

Efisiensi mekanis, $\eta \mathrm{m}$

$$
\eta \mathrm{m}=\frac{P e}{P i}
$$

dimana :

$$
\text { Pe : tekanan efektif } 6,2 \mathrm{~kg} / \mathrm{cm}^{2}
$$

$\mathrm{Pi}$ : tekanan indikatur $8,1 \mathrm{~kg} / \mathrm{cm}^{2}$

maka :

$$
\eta \mathrm{m}=\frac{6.2}{8.1}=76.54 \%
$$

Daya indikatur, Ni

$$
\mathrm{Ni}=\frac{N e}{\eta \mathrm{m}}
$$

dimana :

$$
\begin{gathered}
\mathrm{Ne}: \text { daya motor efektif }=190 \mathrm{pk} \\
\mathrm{Ni}=\frac{190}{0.7654}=248.362 \mathrm{pk}
\end{gathered}
$$

\subsection{Penghitungan Ekonomi dan Neraca Panas Motor}

Pemakaian bahan bakar spesifik indikatur (bi) dihitung menurut persamaan:

$$
\text { bi }=\text { be } . \eta \mathrm{m}
$$

dimana :

$$
\begin{aligned}
& \text { be }=0.25 \mathrm{~kg} / \mathrm{pk} \text { jam } \\
& \eta \mathrm{m}=0,765
\end{aligned}
$$

maka :

$$
\begin{aligned}
& \text { bi }=0,25 \times 0,765 \\
& =0,1913 \mathrm{~kg} / \mathrm{pk} \text { jam }
\end{aligned}
$$

Pemakaian bahan bakar spesifik efektif, be

$$
\text { be }=0.25 \mathrm{~kg} / \mathrm{pk} \text { jam }
$$

Pemakaian bahan bakar tiap jam, $\mathrm{G}_{\mathrm{bb}}$

dimana

$$
\mathrm{G}_{\mathrm{bb}}=\text { be } . \mathrm{Ne}
$$

maka :

$$
\mathrm{Ne}=190 \mathrm{pk}
$$

$$
\begin{gathered}
\mathrm{G}_{\mathrm{bb}}=0,25 \times 190 \\
=47,5 \mathrm{~kg} / \mathrm{jam}
\end{gathered}
$$




\section{Efisiensi Thermis $\left(\boldsymbol{\eta}_{\mathrm{ti}}\right)$}

- $\quad$ Efisiensi thermis indikatur $\left(\eta_{\mathrm{ti}}\right)$ dimana :

$$
\eta_{\mathrm{ti}}=\frac{632}{b i . H i}
$$

$$
\begin{aligned}
& \mathrm{H}_{\mathrm{I}}: \text { nilai kalor bahan bakar } \\
& =10.100 \mathrm{kcal} / \mathrm{kg} \\
& \eta_{\mathrm{ti}}=\frac{632}{0.1913 .10 .100} \times 100 \%=33.04 \%
\end{aligned}
$$

- $\quad$ Efisiensi thermis efektif $\left(\eta_{\mathrm{te}}\right)$

$$
\begin{aligned}
\eta_{\mathrm{te}} & =\eta_{\mathrm{ti}} \cdot \eta_{\mathrm{m}} \\
& =0,3304 \times 0,765 \times 100 \% \\
& =25,28 \%
\end{aligned}
$$

- Panas yang dihasilkan oleh $\mathrm{G}_{\mathrm{bb}} \mathrm{kgbb}$ dalam pembakaran sempurna $\left(\mathrm{Q}_{\mathrm{r}}\right)$

dimana :

$$
\mathrm{Q}_{\mathrm{f}}=\mathrm{G}_{\mathrm{bb}} \cdot \mathrm{H}_{\mathrm{I}}
$$

$\mathrm{G}_{\mathrm{bb}}$ : Pemakaian bahan bakar tiap jam.

$\mathrm{Q}_{\mathrm{f}}=40 \mathrm{~kg} / \mathrm{jam} \times 10100=404.000$ $\mathrm{kal} / \mathrm{jam}$

- Jumlah panas yang dirubah menjadi tenaga efektif $Q_{\mathrm{e}}$

$$
\mathrm{Q}_{\mathrm{e}}=632 . \mathrm{N}_{\mathrm{e}}
$$

dimana $: \mathrm{Ne}=190 \mathrm{pk}$

maka :

$$
\begin{aligned}
\mathrm{Q}_{\mathrm{e}} & =632 \times 190 \\
& =120.080 \mathrm{kal} / \mathrm{jam}
\end{aligned}
$$

$$
\begin{aligned}
& \text { Qe } \%=\frac{Q e}{Q f} \times 100 \% \\
& \text { Qe }=\frac{120.080}{400.000} \times 100 \%=31 \%
\end{aligned}
$$

Konsumsi Udara Teoritis (Mth)

dimana :

$$
\mathrm{M}_{\mathrm{th}}=\mathrm{VI} \cdot 10^{-4} \cdot \mathrm{N} \cdot 60 \cdot \rho_{\mathrm{ud}}
$$

sehingga

$$
\mathrm{N} \text { : Putaran motor ; } 620 \mathrm{rpm}
$$$$
\rho_{\text {ud }}: 1,2327 \mathrm{~kg} / \mathrm{m}^{3} \text { (massa jenis udara) }
$$

\begin{tabular}{|c|c|c|c|}
\hline $\begin{array}{l}\text { Efisiensi } \\
\text { termal } \\
\text { indikasi, } \quad \eta \mathrm{ti} \\
(\%)\end{array}$ & 33.04 & 35.03 & 35.31 \\
\hline $\begin{array}{l}\text { Efisiensi } \\
\text { termal efektif, } \\
\eta \text { te }(\%)\end{array}$ & 25.28 & 28.75 & 35.31 \\
\hline $\begin{array}{l}\text { Daya indikasi, } \\
\mathrm{Ni} \text { (pk) }\end{array}$ & 248.366 & 256.098 & 258.090 \\
\hline $\begin{array}{l}\text { Penggunaan } \\
\text { Bahan Bakar, } \\
\text { bi (kg/pk.jam) }\end{array}$ & 0.1913 & 0.1894 & 0.179 \\
\hline $\begin{array}{l}\text { Penggunaan } \\
\text { Bahan Bakar } \\
\text {,be(kg/pk.jam } \\
\text { ) }\end{array}$ & 0.25 & 0.22 & 0.21 \\
\hline $\begin{array}{l}\text { Pemakaian } \\
\text { Bahan Bakar, } \\
\text { B (kg/jam) }\end{array}$ & 47.5 & 46.2 & 46.2 \\
\hline
\end{tabular}

$311 \mathrm{~kg} / \mathrm{jam}$

$$
M_{\text {th }}=67,824 \cdot 10^{-4} \cdot 620.60 \cdot 1,2327=
$$

Konsumsi Udara Aktual (Ma)

dimana :

$$
\mathrm{Ma}=\rho_{\text {ud }} \cdot \pi / 4 . \mathrm{D}^{2} \cdot \mathrm{L} \cdot \mathrm{N} / 60.1 / 2
$$

$60.1 / 2$

$$
\mathrm{Ma}=1,2327 \cdot 3,14 / 4 \cdot(0,2)^{2} \cdot 0,27 \cdot 620 .
$$

$$
=194,38 \mathrm{~kg} / \mathrm{jam}
$$

Efisiensi Volumetrik ( $\eta \mathrm{v})$

$$
\eta_{\mathrm{v}}=\frac{M a}{M t h} \times 100 \%=\frac{194.38}{311} \times 100 \%=62.5 \%
$$

Dengan cara yang sama dihitung untuk penggunaan pertamax dan pertamax plus

Tabel 4.5. Data Kinerja Mesin Toyota XXX

\begin{tabular}{|l|l|l|l|}
\hline Kinerja Mesin & Premium & Pertamax & $\begin{array}{c}\text { Pertamax } \\
\text { Plus }\end{array}$ \\
\hline $\begin{array}{l}\text { Efisiensi } \\
\begin{array}{l}\text { Mekanis, } \eta \mathrm{m} \\
(\%)\end{array}\end{array}$ & 76.54 & 82 & 85.24 \\
\hline
\end{tabular}

\subsection{Pembahasan}

Dari tabel 4.5. diatas terlihat bahwa jika dengan menggunakan bahan bakar pertamax plus dan pertamax, daya indikator yang dihasilkan lebih besar yaitu 258,090 pk dan 256,098 pk jika dibandingkan dengan menggunakan bahan bakar premium yaitu sebesar 248,366 pk, demikian juga dengan daya efektif yang terjadi lebih besar dengan menggunakan pertamax dan pertamax plus ( 210 pk, dan 220pk) hal ini disebabkan karena bahan bakar dari jenis pertamax nilai Oktannya lebih tinggi sehingga terjadi pembakaran secara sempurna yang berakibat pada terjadinya peningkatan daya indikator yang lebih besar juga.

Nilai efisiensi termal efektif dari jenis pertamax plus lebih tinggi jika dengan mengunakan bahan bakar pertamax dan premium hal ini disebabkan karena dengan menggunakan bahan bakar pertamax plus penggunaan bahan bakar spesifik lebih lebih tinggi sehingga penggunaaan bahan bakarnya juga lebih besar disamping itu juga karena terlalu banyaknya $\mathrm{CO}$ yang terbentuk sehingga pembakaran tidak sempurna.

\section{Kesimpulan}

\subsection{Kesimpulan}

1. Dari penelitian yang dilakukan, pertamax plus merupakan bahan bakar dengan tingkat emisi yang rendah.

2. Dengan menggunakan pertamax plus daya indikasi mesin dan daya efektif mesin lebih tinggi bila dibandingkan dengan premium dan pertamax

3. Efisiensi termal efektif dengan bahan bakar pertamax plus lebih tinggi $(35,31 \%)$ jika dibandingkan dengan bahan bakar premium 
yaitu sebesar 27,09\%.Dengan demikian panas yang dihasilkan saat pembakaran untuk mesin yang menggunakan pertamax plus lebih banyak termanfaat sebagai tenaga efektif.

\subsection{Saran}

1. Gunakan bahanbakar dengan angka oktan yang sesuai dengan tekanan kompresi kendaraan. Untuk kendaraan dengan perbandingan kompresi $\leq 9$ : 1 ; gunakan premium, untuk kendaraan dengan perbandingan kompresi antara 9.1 - 10.1; gunakan pertamax dan untuk kendaraan dengan perbandingan kompresi antara 10.1 - 11.1; gunakan pertamax plus.

2. Agar mendpapatkan kadar emisi HC yang sesuai dengan standar uji emisi maka sebaiknya sering - sering melakukan pengecekan pada sistem pengapian apakah masih dalam batas normal atau tidak, periksa intake manifold terdapat kebocoran atau tidak, dan AFR masih normal, tidak terlalu kurus atau tidak terlalau kaya.

3. Untuk mendapatkan kadar $\mathrm{CO} 2$ tetap tinggi, pastikan agar ruang bakar dan Catalytic Converter tetap dalam kondisi normal.

4. Selalu lakukan pengecekan pada air filter, fuel filter, injektor, busi, sensor oksigen, throttle body agar hasil emisi gas buang di ambang batas normal.

\section{DAFTAR PUSTAKA}

1. Anonim.t.th.News Step 2Engine Group. Jakarta. PT Toyota Astra Motor langitbiru.menlh.go.id

2. kphmph.wordpress.com/2012/12/18; Pengetahuan bensin, premium, pertamax, pertamax plus

3. /http/www pertamina.com

4. /http//www.saft7.com/emisi gas buang

5. Petrovsky, N; marine internal combustion engines, mir Publishers, Moscow

6. Permen RI No. 41 tahun 1999, tentang Pengendalian Pencemaran Udara

7. Permen LH No. 04/2009, tentang Ambang Batas Emisi Gas Buang Kendaraan Bermotor tipe baru

8. Saragih Rapotan dan Joko Sungkono Kawano; pengaruh penggunaan bahan bakar premium-pertamax-pertamax plus dan spritus terhadap unjuk kerja engine genset 4 langkah; jurnal Teknik Pomits vol 2 No. 1 tahun 2013

9. UU No 32 tahun tahun 2009 tentang perlindungan dan pengelolaan lingkungan

10. PP No. 41/2013 tentang barang kena pajak yang tergolong mewah berupa kendaraan bermotor yang dikenai pajak penjualan barang mewah

11. PP No. 22 tahun 2014 tentang perubahan atas PP No. 41 tahun 201 